See discussions, stats, and author profiles for this publication at: https://www.researchgate.net/publication/315366592

\title{
Atomistic study on shock behaviour of NiTi shape memory alloy
}

Article in Philosophical Magazine · February 2017

DOI: 10.1080/14786435.2017.1294769

\section{CITATION}

1

3 authors:

Yin Qiuyun

Chinese Academy of Sciences

10 PUBLICATIONS 27 CITATIONS

SEE PROFILE

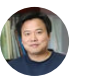

Chenguang Huang

Chinese Academy of Sciences

155 PUBLICATIONS 613 CITATIONS

SEE PROFILE

Some of the authors of this publication are also working on these related projects:

Cavitating flow near free surface View project

Project the interaction of bubbles with shock waves View project

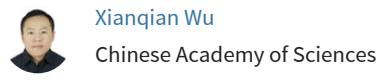
43 PUBLICATIONS 203 CITATIONS

SEE PROFILE 


\section{Atomistic study on shock behaviour of NiTi shape memory alloy}

\section{Qiuyun Yin, Xianqian Wu \& Chenguang Huang}

To cite this article: Qiuyun Yin, Xianqian Wu \& Chenguang Huang (2017): Atomistic study on shock behaviour of NiTi shape memory alloy, Philosophical Magazine, DOI: 10.1080/14786435.2017.1294769

To link to this article: http://dx.doi.org/10.1080/14786435.2017.1294769

曲 Published online: 21 Feb 2017.

Submit your article to this journal

Џll Article views: 13

Q View related articles $₫$

View Crossmark data \lceil 


\title{
Atomistic study on shock behaviour of NiTi shape memory alloy
}

\author{
Qiuyun Yin ${ }^{\mathrm{a}, \mathrm{c}}$, Xianqian Wu $\mathrm{u}^{\mathrm{a}, \mathrm{b}, \mathrm{c}}$ and Chenguang Huang ${ }^{\mathrm{a}, \mathrm{c}}$
}

aKey Laboratory of Mechanics in Fluid Solid Coupling Systems, Institute of Mechanics, Chinese Academy of Sciences, Beijing, P.R. China; 'bState Key Laboratory of Explosion Science and Technology, Beijing Institute of Technology, Beijing, P.R. China; 'School of Engineering Science, University of Chinese Academy of Sciences, Beijing, P.R. China

\begin{abstract}
The shock behaviour of NiTi shape memory alloy is investigated by using molecular dynamics simulation. The nano-pillar samples of the alloy are subjected to the impact of a piston with a velocity of $350 \mathrm{~m} / \mathrm{s}$ at initial environment temperatures of 325 and $500 \mathrm{~K}$. At $325 \mathrm{~K}$, we observe two different pathways of the formation of BCO phase, the gradient twins, and the detwinning phenomena, strongly depending on the local stress and the deformation state. As the initial temperature increases to $500 \mathrm{~K}$, the plasticity is dominated by the dislocation movements rather than the twinning at $325 \mathrm{~K}$. The phase transformation and plasticity result in stress attenuation when the stress wave propagates through the nano-pillar. Furthermore, it is interesting to note that multiple stress peaks occur due to the formation of local complex atomic structures with various wave speeds, leading to the catch up and overlap of the stress waves.
\end{abstract}

\section{ARTICLE HISTORY}

Received 20 October 2016

Accepted 9 February 2017

\section{KEYWORDS}

$\mathrm{NiTi}$ shape memory alloys; molecular dynamics; phase transformation; plasticity; stress waves

\section{Introduction}

Shape memory alloys (SMAs) have attracted great attention in the past decades. SMAs can totally recover to the initial state with the aid of heat after experiencing a large deformation at low temperature as a result of phase transformation $[1,2]$. In addition, the phase transformation and reverse phase transformation between the austenite phase and the martensite phase can lead to the so-called pseudo-elasticity (also called the super-elasticity, SE). It has a recoverable strain up to $8 \%$ during loading [1-3]. Due to these unique properties, SMAs are widely used in various engineering fields, such as aerospace $[2,4]$, biomedical $[5,6]$ and mobile phone antennae, to name a few. 
NiTi alloy is a typical SMA. When the testing temperature is close to the austenite finish temperature $\left(A_{f}\right)$ [7], a parent austenite phase (B2, CsCl structure) of NiTi alloy will transform to the martensite phase (B19', monoclinic structure) under loading as concerned with SE. In addition, the NiTi austenite phase will transform to the martensite phase upon cooling while retransform to the initial austenite phase with aid of heating as concerned with the shape memory effect (SME). Numerous experiments have been performed to study the properties of NiTi alloys [8-12]. Chen et al. [13] studied the mechanical behaviour of NiTi alloys at strain rates ranging from $10^{-3}$ to $750 \mathrm{~s}^{-1}$. It was found that there was a hysteresis loop in the stress-strain curve, the typical property of SMAs that makes SMAs to be described as 'quiet' alloys [14]. In addition, the hysteresis loop was closed under quasi-static compression while initial residual strain was observed under dynamic loading, which would recover to its length slowly in seconds to hours. Liu et al. [9] found that the compressive stress-strain relationship of NiTi was insensitive to strain rates in a range of $10^{-4}$ to $10^{3} \mathrm{~s}^{-1}$. Furthermore, the post differential scanning calorimetry (DSC) results showed that the stabilization of martensite after deformation was independent to strain rates up to $10^{3} \mathrm{~s}^{-1}$. Nemat-Nasser et al. [7,15] studied the dynamic compressive behaviour of NiTi at strain rates in a range of $10^{-3}$ to $10^{4} \mathrm{~s}^{-1}$ and temperatures in a range of 77 to $400 \mathrm{~K}$ through split Hopkinson pressure bar (SHPB). The results showed that the phase transformation stress increased with the increase of strain rates and the decrease of temperatures. In addition, it was presumed that there was a critical strain rate at a level of about $17,000 \mathrm{~s}^{-1}$ for the phase transformation from the parent B2 phase to the martensite B19' phase. However, Liao et al. [16] observed the residual martensite after shocked at a strain rate up to $10^{7} \mathrm{~s}^{-1}$ through laser shock peening, which left a controversy on the mechanisms of deformation modes of NiTi at high strain rates.

Recently, a number of researchers focused on the micro-structure development of SMAs associated with the SME and SE. To do this, the molecular dynamics (MD) simulation method was adopted since it can conveniently capture details at atomic level and reveal intrinsic mechanisms of materials [17-19]. Mutter et al. [20] explained the difference between the martensite phase transformation starting temperature $\left(M_{s}\right)$ and the finishing temperature $\left(M_{f}\right)$ by illustrating origination and development of the $\mathrm{B} 19^{\prime} \rightarrow \mathrm{B} 2$ phase transformation in a nano-sphere. They also constructed the relationship between the phase transformation temperature and the size of nano-particles. Sato et al. [19] performed the MD simulation of NiTi nano-pillar under athermal tensile loading at various strain rates. It was found that there were different pathways from the initial austenite phase to the martensite phase during loading, and the pathways were sensitive to loading rates. Zhong et al. $[17,21]$ performed the MD simulation to study the nano-twinned structure of NiTi SMAs. A novel nano-twinned structure formation was observed during the martensite phase transformation, and the phase transformation temperature was well predicted. In addition, it was found that the NiTi nano-pillar experienced 
Table 1. Potential parameters for NiTi.

\begin{tabular}{lccccccccc}
\hline Parameters & $D(\AA)$ & $A(\mathrm{eV})$ & $p$ & $\xi(\mathrm{eV})$ & $Q$ & \multicolumn{1}{c}{$c_{0}$} & \multicolumn{1}{c}{$c_{1}$} & \multicolumn{1}{c}{$c_{2}$} & $c_{3}$ \\
\hline $\mathrm{Ni}-\mathrm{Ni}$ & 2.490 & 0.104 & 11.198 & 1.591 & 2.413 & 0.13561 & -0.26286 & -7.54308 & 27.3341 \\
$\mathrm{Ti}-\mathrm{Ti}$ & 2.950 & 0.153 & 9.253 & 1.879 & 2.513 & 0.59012 & -1.0054 & -34.205 & 122.395 \\
$\mathrm{Ni}-\mathrm{Ti}$ & 2.607 & 0.300 & 7.900 & 2.480 & 3.002 & 0.248676 & -0.572708 & -12.92362 & 47.8513 \\
\hline
\end{tabular}

the phase transformation from $\mathrm{B} 2 \rightarrow \mathrm{B} 19 \rightarrow \mathrm{B} 19^{\prime} \rightarrow \mathrm{BCO}$ when subjected to uniform compression at 350 and $400 \mathrm{~K}$, respectively. It was observed that the phase transformation stress from $\mathrm{B} 2 \rightarrow \mathrm{B} 19$ increased with increasing temperature. In our previous work, the temperature and the strain rate-dependent phase transformation behaviour of NiTi nano-pillar under uniform compression were studied [22]. It was found that the phase transformation stress from B2 $\rightarrow$ B19 was insensitive to the strain rate but strongly dependent to the environment temperature. Moreover, the phase transformation stress from $\mathrm{B} 19 \rightarrow \mathrm{B} 19^{\prime}$ increased with the increase of strain rate and the decrease of temperature. A phase diagram of NiTi at various temperatures and strain rates was given [22], which could qualitatively explain the controversial observations of Nemat-Nasser et al. [7,23] and Liao et al. [16].

The complex plasticity and transformation behaviours of NiTi are very complex at various stresses, strain rates and ambient temperatures. The behaviours during the propagation of shock wave are important to further understand the dynamic response of NiTi under shock as studied by Liao et al. [16]. However, due to the limitation of measurement instruments, it is difficult to investigate the dynamic behaviour of NiTi through direct experiments., In the present research, the shock response and the shock attenuation behaviour of NiTi are investigated through MD simulations. We consider the effects of adiabatic temperature rising and stress attenuation on the phase transformation behaviour of NiTi during shock wave propagating. Multiple stress wave structures are observed due to the complex transformation of NiTi while shocked, which could be well explained by the phase diagram obtained in our previous study [22]. We also investigate the development of phase transformation and reverse phase transformation of NiTi nano-pillar as well as the plastic deformation during impact. It is revealed that these behaviours are highly depended on the local stress, temperature and strain rate.

\section{Method}

\subsection{Modelling}

The MD simulation was performed through large scale atom/molecular massively parallel simulation (LAMMPS) [24]. The initial geometry of the NiTi nano-pillar with the parent B2 phase was $50 \mathrm{~nm}$ in length and $4.8 \times 5.1 \mathrm{~nm}$ in cross section. The axis was aligned with $\left[\begin{array}{lll}1 & 1 & 0\end{array}\right]_{\mathrm{B} 2}$ direction. The boundaries in three dimensions were free in trajectory. The movements of the atoms are controlled by the Newton' laws of motion. The,calculation of interatomic force, which relates to the 

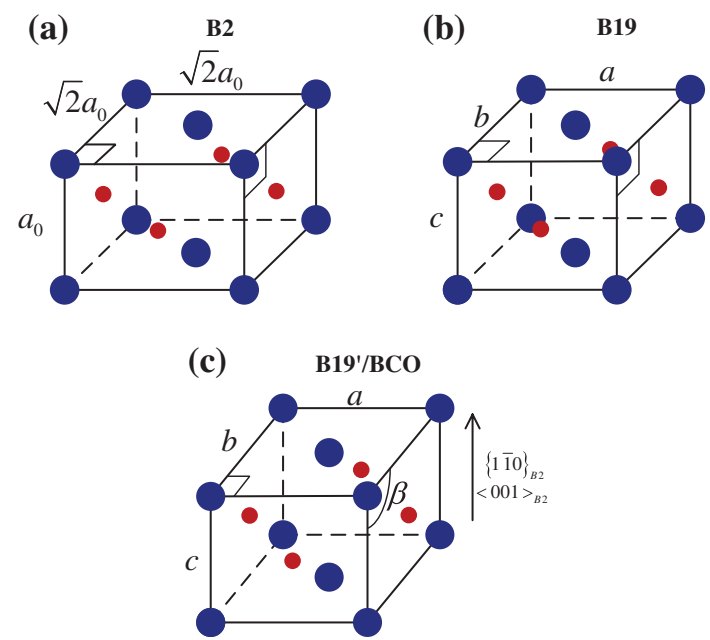

Figure 1. (colour online) Structures of various phases: (a) B2, (b) B19, (c) B19'/BCO ( $\beta=98^{\circ}$ for B19' and $\beta=108^{\circ}$ for $\left.\mathrm{BCO}\right)$.

interatomic potential, is the kernel of MD simulation. Here we adopted a many body interatomic potential which was originally developed by Lai et al. [25] and subsequently improved by Zhong et al. [21]. The potential parameters were fitted through the first principle calculation at the temperature of $0 \mathrm{~K}$ by Lai et al. [25] while the cutoff zone of the potential function was smoothed by Zhong et al. [21] to make it suitable for dynamics simulations. The modified potential of NiTi, which could well predict the properties of NiTi such as the lattice parameters and the cohesive energy, is expressed as following,

$$
E=\sum_{i}\left\{\sum_{j \neq i} A_{\alpha \beta} \exp \left[-p_{\alpha \beta}\left(\frac{r_{i j}}{\sigma_{\alpha \beta}}-1\right)\right]-\sqrt{\sum_{j \neq i} F_{i j}}\right\}
$$

where

$$
F_{i j}= \begin{cases}\xi_{\alpha \beta}^{2} \exp \left[-2 q_{\alpha \beta}\left(\frac{r_{i j}}{\sigma_{\alpha \beta}}-1\right)\right], & r_{i j}<r_{1} \quad(2) \\ c_{3, \alpha \beta}\left(r_{i j}-r_{1}\right)^{3}+c_{2, \alpha \beta}\left(r_{i j}-r_{1}\right)^{2}+c_{1, \alpha \beta}\left(r_{i j}-r_{1}\right)+c_{0, \alpha \beta}, & r_{1}<r_{i j}<r_{c}\end{cases}
$$

Here $E$ denotes the total potential energy of the system. The first item on the right hand side in the bracket in the Equation (1) describes the interacted potential of two adjacent atoms, and the second item describes the many body potential according to the theory of electronic cloud density. In addition, $\sigma_{\alpha \beta}$ denotes the equilibrium distance of two different types of atoms denoted by $\alpha$ and $\beta$, respectively, and $r_{i j}$ denotes the current distance between atoms $i$ and $j$. The cutoff distance $r_{c}$ and the smoothing transition distance $r_{1}$ are 4.2 and $4.0 \AA$, respectively, 
according to the previous study [21]. The rest parameters are either determined by the first principle theory or derived from the many body function $F$ according to $r_{1}$ to ensure the continuity at the smooth transition zone. These potential related parameters were given in Table 1.

The Nose-Hoover thermostat [26] was applied to control the temperature in thermal equilibrium. The initial equilibrium temperatures were $325 \mathrm{~K}$ (above the starting temperature of martensite phase transformation, $M_{s}$ ) and $500 \mathrm{~K}$ (high enough for B2 phase to be stable), respectively. Here, the equilibrium temperature of $325 \mathrm{~K}$ was chosen because it was a critical temperature between the martensite phase transformation starting temperature, $M_{s}$, and the austenite phase transformation starting temperature, $A_{s}$. It meant that, the crystal structure at this temperature would be determined by the way the initial crystal structure was formed. For example, the B2 phase would be stable if the sample was cooled down from a higher temperature while the B19 phase would be stable if it was heated from a lower temperature. In the present study, the initial configured structure was B2 and the annealing temperature was $325 \mathrm{~K}$, indicating that the $\mathrm{B} 2$ phase would be the stable phase if there were no changes of temperature or stress. However, the system we configured was actually free in three dimensions. As a result, the free surface force would act as an 'external force' and drive the B2 to B19 phase transformation $[17,22]$, resulting in the stable B19 phase in this condition at the beginning of loading. The time increment was $0.5 \mathrm{fs}$, which was short enough for both the thermal equilibrium and the loading period. The thermal equilibrium was achieved in a sufficient long time of 100 ps. After that, the system was set to free using NVE ensemble, i.e. without energy and mass exchanges with the environment, leading to an adiabatic system during impact loading and an initiation period of wave propagation. Here, the adiabatic ensemble was taken because we focused on the dynamic behaviour of the NiTi nano-pillar under high pressures with a short duration. The interaction time was so short that it was generally considered to be adiabatic in experiments. To study the dynamic behaviour of the NiTi under impact, 5 layers' atoms with a total thickness of about $2 \mathrm{~nm}$ at the left end of the nano-pillar was set to the impact piston [27], which was forced to move rightwards with a speed of $350 \mathrm{~m} / \mathrm{s}$ and a duration of 3.0 ps to induce a shock wave propagating through the nano-pillar, resulting in a nominal loading rate of about $2.3 \times 10^{10} \mathrm{~s}^{-1}$ and a shock pressure much higher than the phase transformation stress and the yield stress of the NiTi alloys. The local atomic structures and common neighbour analysis (CNA) $[28,29]$ were illustrated to describe the phase transformation and the plastic deformation evolution during the propagation of shock wave. The microstructures of various phases of NiTi are shown in Figure 1. Here the different phase structures are distinguished by the lattice parameter, i.e. the bond-angle $\beta$ is $90^{\circ}$ for $\mathrm{B} 2$ phase, $98^{\circ}$ for $\mathrm{B} 19^{\prime}$ phase, and $108^{\circ}$ for $\mathrm{BCO}$ [21], and CNA values, e.g. 3 for BCC and 5 for unknown structures which indicate the B19'/BCO phase or structures at the free surface and defects regions in the present study. However, CNA is unable to distinguish the phases of B2 and B19 


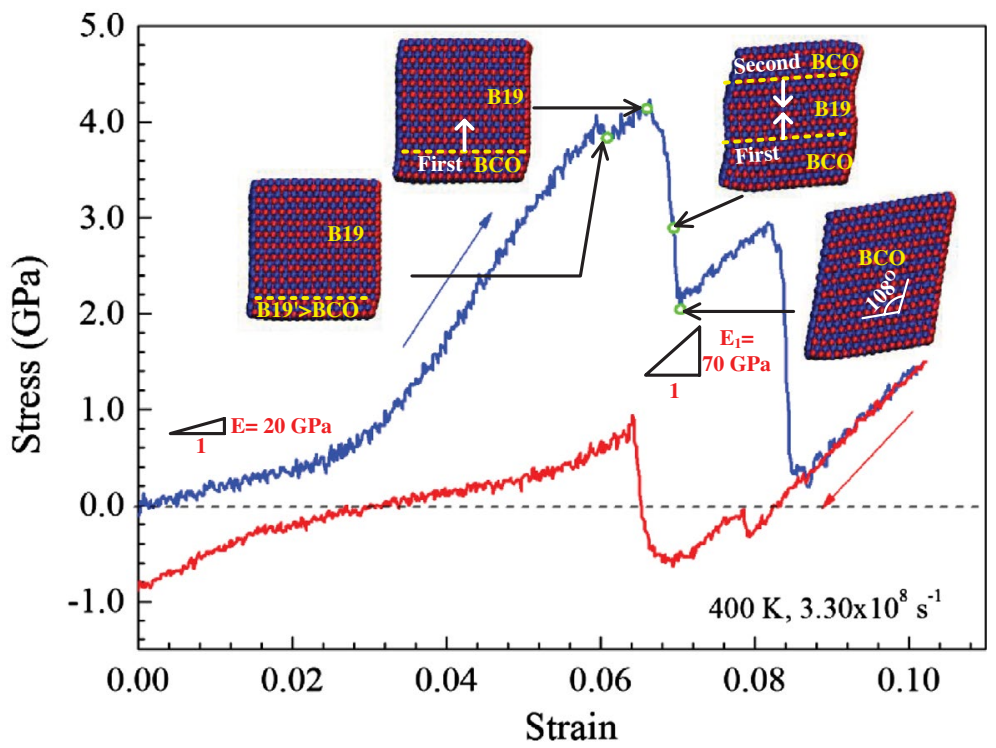

Figure 2. (colour online) Compression of the NiTi nano-pillar at $400 \mathrm{~K}$ and at a constant strain rate of $3.3 \times 10^{8} \mathrm{~s}^{-1}$.

due to the similitude of their neighbourhood structures. Note that the compressive stress is taken as positive in the present study. The stresses are calculated by the Virial method and averaged on 100 time steps to reduce thermal fluctuations. In addition, the temperatures are calculated according to the velocities of atoms with the formula $T=\sum_{i} m_{i} v_{i}^{2} /(\operatorname{dim} \cdot k \cdot N)$, where $\operatorname{dim}$ denotes the dimension of the system ( $\operatorname{dim}=3$ in this case), $k$ is the Boltzmann constant and $N$ is the number of atoms in the calculation regions.

\subsection{Validation}

In order to validate the present MD modelling, the phase transformation under strain controlled uniaxial compression at a strain rate of $10^{8} \mathrm{~s}^{-1}$ was investigated as our previous study [22]. The results were the same as the observation of Zhong et al. [17], in which the Young's modulus of the B2 was compared and consistent with the measurement of Brill et al. [30] and the ab initial density functional theory calculations of Hatcher et al. [31] and Wagner and Windl [32]. As shown in Figure 2, the NiTi nano-pillar was observed to experience an elastic deformation as well as a phase transformation to the $\mathrm{BCO}$ phase. Although the $\mathrm{BCO}$ phase was not observed in experiments, it could be regarded as a special case of the B19' structure as studied by Huang et al. [33]. From this point of view, the effective Young's modulus of the $\mathrm{BCO}$ was estimated to about $70 \mathrm{GPa}$ according to the slop of stress-strain curve. This value is close to $94.4 \mathrm{GPa}$ of orientation-specific Young's modulus obtained by Stebner et al. [34]. In addition, it could be seen that the potential well captured the complex phase transformation behaviour of 
(a)

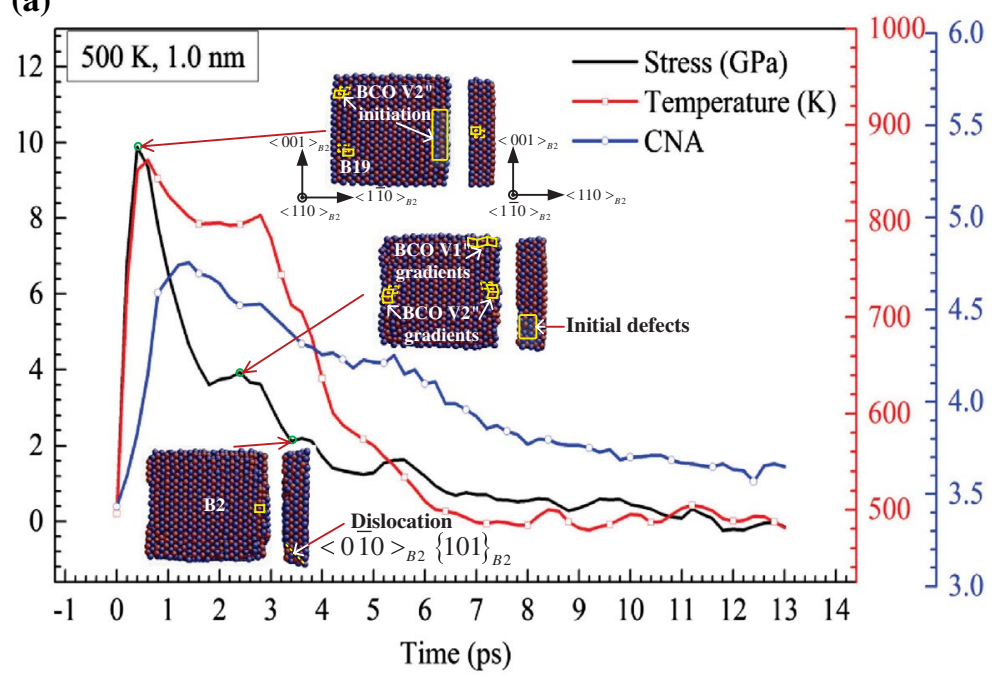

(b)

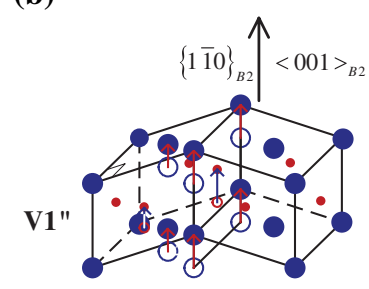

I

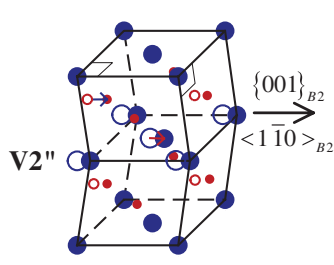

II

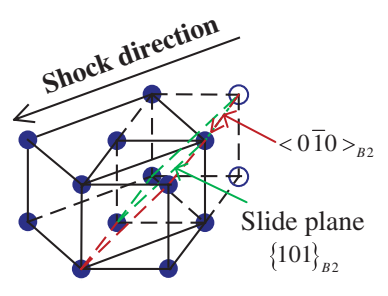

III

Figure 3. (colour online) (a) Stress history, cross section atomic structure, temperature evolution and corresponding CNA history at the impact end area at initial temperature $500 \mathrm{~K}$. (b) Atomic structure change in this cross section area.

the NiTi nano-pillar under extremely high strain rate compression, indicating its validity for dynamic simulations.

\section{Results and discussion}

\subsection{Phase transformation and dislocation slide}

In this section, the initial thermal equilibrium temperature of $500 \mathrm{~K}$, which is much higher than the transformation temperature from austenite phase to martensite phase, was simulated to study the dynamic behaviour of NiTi nano-pillar with initial stable B2 phase under impact. Figures 3-5 show the stress, temperature and CNA histories as well as the atomic structure evolutions at the impact end area (about $1.0 \mathrm{~nm}$ away from the impact end), the large deformation area (about $3.4 \mathrm{~nm}$ away from the impact end) and the silent area (about $13.0 \mathrm{~nm}$ away from the impact end), respectively. Note that, the stresses and CNA values were 
(a)

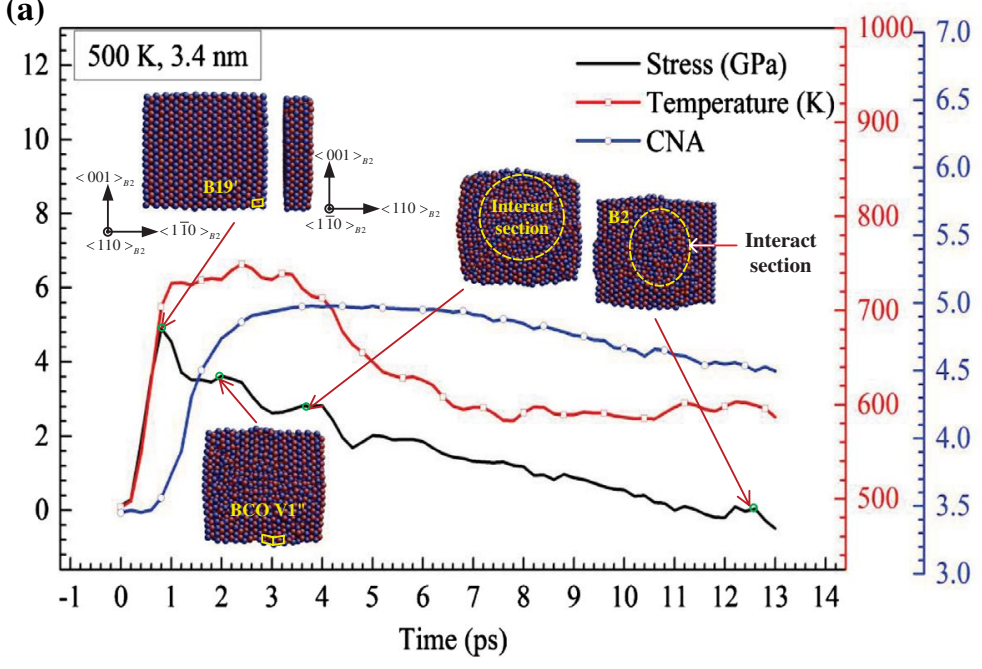

(b)

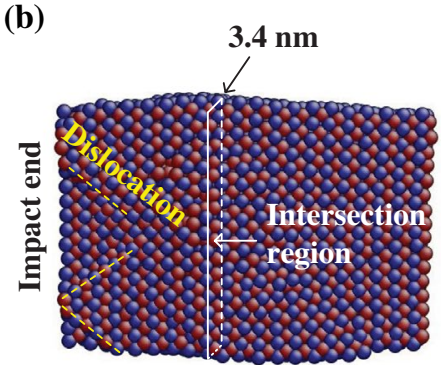

$3.8 \mathrm{ps}$

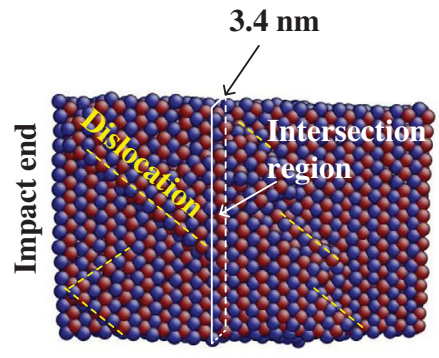

$13.0 \mathrm{ps}$

Figure 4. (colour online) (a) Stress history, cross section atomic structure, temperature evolution and corresponding CNA history at the large deformation area at initial temperature $500 \mathrm{~K}$. (b) Multiple dislocations development.

averaged on a group of atoms in the plate with a thickness of $1.2 \mathrm{~nm}$ perpendicular to the axis.

As shown in Figure 3, the BCO V1" and BCO V2" structures were formed by the sliding modes I and II, respectively. The mode I is the sliding of $\{1 \overline{1} 0\}_{B 2}$ crystal plane in crystal direction of $\langle 001\rangle_{\mathrm{B} 2}$ [17], and the mode II is the sliding of $\left\{\begin{array}{lll}0 & 0 & 1\end{array}\right\}_{\mathrm{B} 2}$ crystal plane in the crystal direction of $\left.<\begin{array}{lll}1 & \overline{1} & 0\end{array}\right\rangle_{\mathrm{B} 2}$ [35]. Both of the two transformation modes have been observed in experiments [36,37], and the mode I is more likely to occur at relatively low stress state while the mode II is preferred to occur at relatively high stress state [38]. As shown in Figure 3(a), at the beginning the stress increased significantly to a peak value of about $9.9 \mathrm{GPa}$ at $0.4 \mathrm{ps}$, and the corresponding temperature increased abruptly from $500 \mathrm{~K}$ to about $863 \mathrm{~K}$. Due to the high stress amplitude, the initial B2 phase experienced a phase transformation $\mathrm{B} 2 \rightarrow \mathrm{B} 19$ and then partially to $\mathrm{BCO}$ V2" variants, leading to the increase of corresponding CNA from about 3.5 to about 4.7 at $1.4 \mathrm{ps}$. The average 


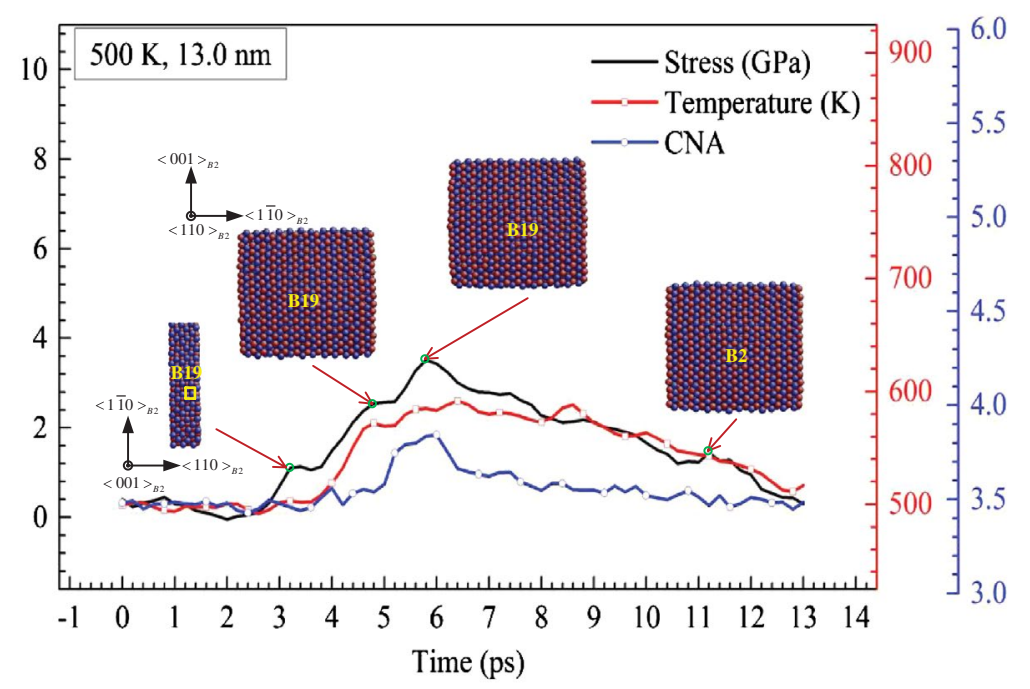

Figure 5. (colour online) Stress history, cross section atomic structure, temperature evolution and corresponding CNA history at the area far from the impact end at initial temperature $500 \mathrm{~K}$.

CNA value at the beginning of loading was about 3.5 due to the effect of surface atoms with an imperfect neighbourhood. Note that the phase transformation just occurred in a few number of unit cells. The formation and consequential evolution of the BCO V2" variant leaded to the abrupt decreases of stress to about 3.6 GPa and temperature to about $797 \mathrm{~K}$ at $1.8 \mathrm{ps}$. Then the stress slightly increased to about $3.9 \mathrm{GPa}$ at $2.2 \mathrm{ps}$. After that, the stress experienced a second drop from about 3.6 GPa at 2.8 ps to about 2.1 GPa at $3.4 \mathrm{ps}$. Correspondingly, the temperature decreased abruptly from about $800 \mathrm{~K}$ to about $710 \mathrm{~K}$. Note that the formation of BCO V1" variant gradients was observed during the first abruptly drop of stress. The de-twinning of the $\mathrm{BCO}$ phase gradients and the reverse transformation from the $\mathrm{BCO}$ phase to the final B2 phase were observed due to the local adiabatic temperature rising induced by dynamic compression as shown in Figure 3(a). This gave rise to a slightly increase of the stress, leading to a stress plateau during unloading. In addition, because of the high stress state and high temperature, the initiation of defects that observed during the first stress drop acted as obstacles for the phase transformation and was beneficial to the reverse transformation. The corresponding CNA value decreased continually during the unloading process, which also provided the evidence of the reverse transformation from the BCO phase to the B2 phase. Note that due to the formation of dislocations, the CNA value was about 3.6 at the end of simulation, which was a little higher than the initial value of 3.5. Also, a sudden decrease of stress occurred after the formation of dislocation before unloading, which is consistent with our previous study [22]. 

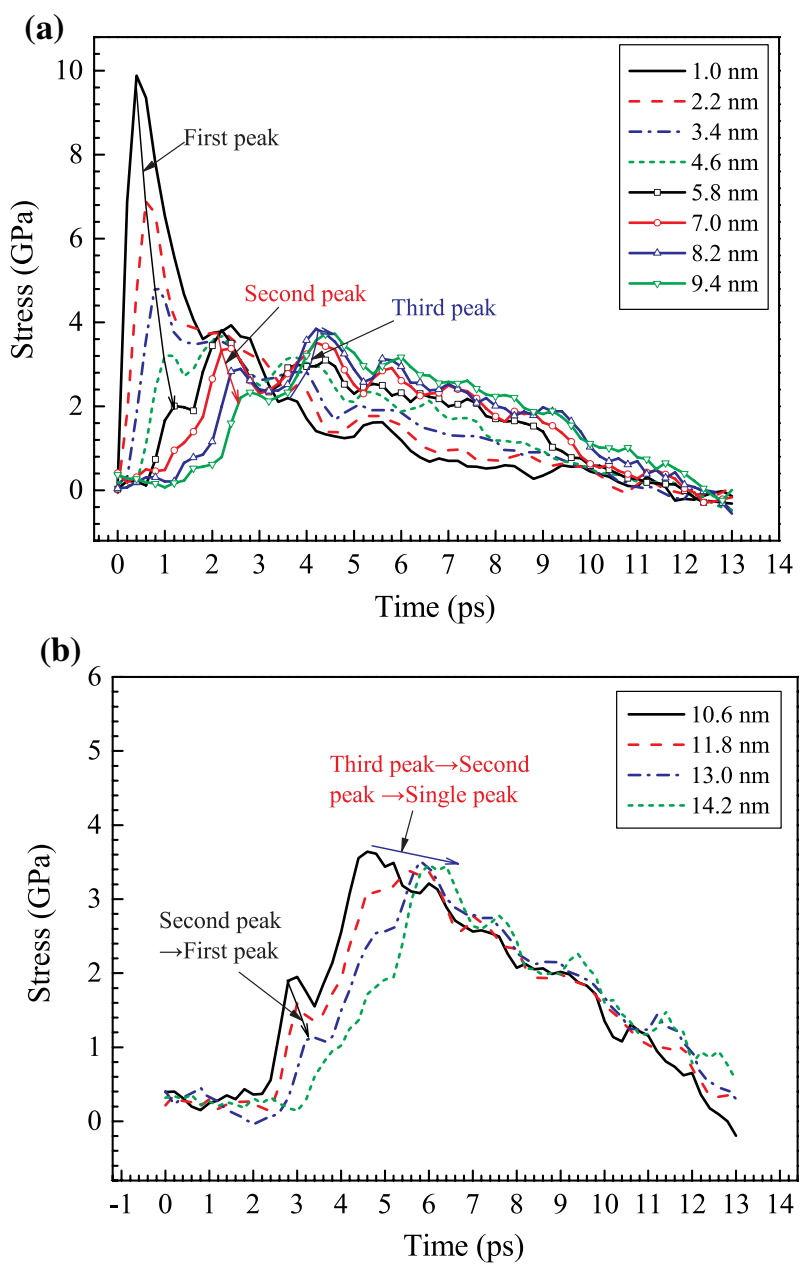

Figure 6. (colour online) Stress histories of different NiTi nano-pillar cross section layers (a) from 1.0 to $9.4 \mathrm{~nm}$ away from impact end and (b) from 10.6 to $14.2 \mathrm{~nm}$ away from impact end at initial temperature $500 \mathrm{~K}$.

With the propagation of the shock wave, the peak stress decreased quickly and the stress profile became much wide at the cross section layer of $3.4 \mathrm{~nm}$ away from the impact section, which experienced relative large deformation during the impact, as shown in Figure 4(a). At the beginning, the stress increased rapidly from about $0.2 \mathrm{GPa}$ at $0.2 \mathrm{ps}$ to a peak value of about $4.9 \mathrm{GPa}$ at $0.8 \mathrm{ps}$, and the corresponding temperature increased from $500 \mathrm{~K}$ to about $729 \mathrm{~K}$. The relative high stress induced the phase transformation from the parent $\mathrm{B} 2$ to the $\mathrm{B} 19^{\prime}$ phase at the near surface region, where the crystal cells were less confined [20]. Due to the formation of the B19' phase, the corresponding CNA value slightly increased from about 3.5 to about 3.8 at 0.8 ps. Then the stress decreased to about $3.5 \mathrm{GPa}$ at 1.4 ps. After that, we observed a second sharp drop of stress from $3.5 \mathrm{GPa}$ at 2.4 ps to about $2.6 \mathrm{GPa}$ at $3.0 \mathrm{ps}$. However, the temperature was kept at $729 \mathrm{~K}$ 


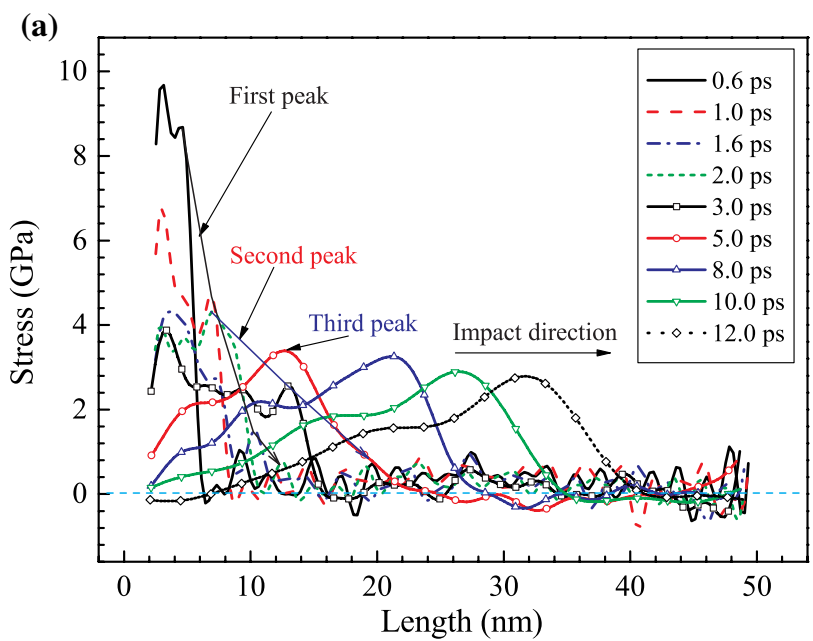

(b)
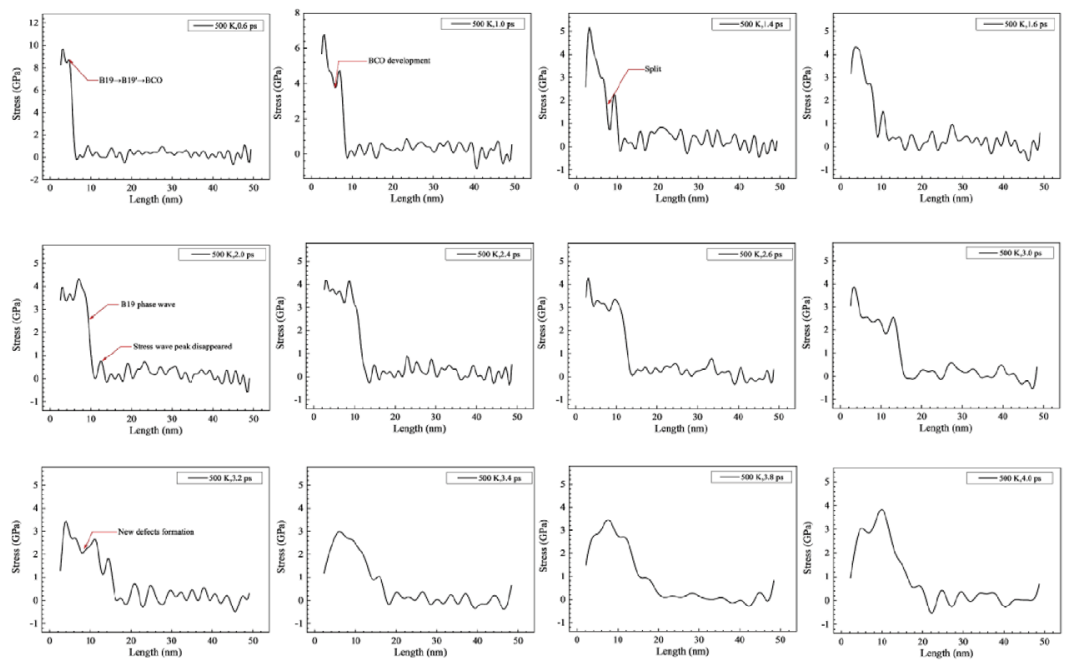

(c)

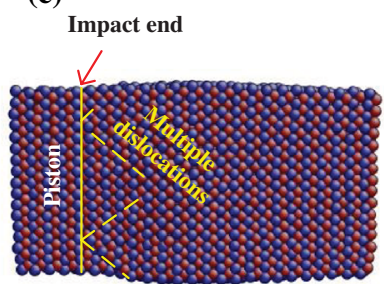

$2.0 \mathrm{ps}$

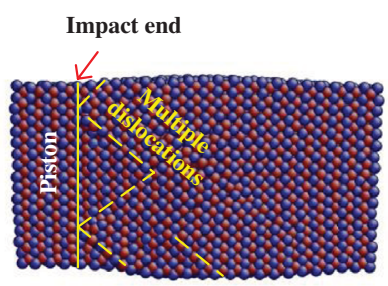

$2.6 \mathrm{ps}$

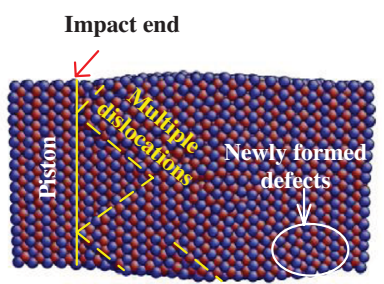

$3.2 \mathrm{ps}$

Figure 7. (colour online) (a) Stress distribution along the NiTi nano-pillar at different time at the initial temperature $500 \mathrm{~K}$. (b) Detailed stress distribution change from 0.6 to $4.0 \mathrm{ps}$ after impact, showing the geometry change of stress wave from cubic to triangular. (c) Formation and evolution of the dislocations. 
from 1.4 ps to $2.0 \mathrm{ps}$ and then increased to about $749 \mathrm{~K}$ at $2.4 \mathrm{ps}$. The reason is possibly due to the work of shock wave, the exothermic transformation from B19 phase to BCO phase, as well as the energy release during formation of defects. The corresponding CNA change could also reflect the complex phase change and the formation of dislocations. Due to the formation of the BCO phase, the CNA value increased quickly from about 3.8 at 0.8 ps to about 5.0 at 3.4 ps. Then, it decreased slightly to about 4.9 at 6.8 ps. After that, the decrease of CNA value accelerated due to the fast reverse transformation from the $\mathrm{BCO}$ phase to the $\mathrm{B} 19$ phase and then to the B2 phase because of the relative high temperature and low stress state. At the end of simulation, due to the interact section of dislocations as shown in Figure 4(b), the CNA value stayed at about 4.5. During the initial period of unloading, the stress slightly increased to about $2.8 \mathrm{GPa}$ at $3.8 \mathrm{ps}$ and then slowly decreased to about zero, and the corresponding temperature decreased from about $738 \mathrm{~K}$ at $3.4 \mathrm{ps}$ to about $595 \mathrm{~K}$ at $6.8 \mathrm{ps}$. It was interesting to note that the durations of stress plateaus during unloading were much wide at this cross section layer when compared to that at the near impact section as shown in Figure 3(a). This could be well understood by the change of shock wave speed after the formation of the BCO phase with relative slow wave speed, leading to the separation of stress waves and consequently the stress plateaus during unloading. Similarly, the high adiabatic temperature rising made it easier for atoms to migrate, as shown in Figure 4(b), leading to the formation of dislocation with a slide plane of $\left\{\begin{array}{lll}1 & 0 & 1\end{array}\right\}_{\mathrm{B} 2}$ and a slide direction of $\left\langle\begin{array}{lll}0 & \overline{1} & 0\end{array}\right\rangle_{\mathrm{B} 2}$. Multiple dislocations formation was observed during the unloading process as shown in Figure 4(a) and (b). With continuously unloading, the dislocations were kept, whereas the surrounding BCO phase was retransformed to the $\mathrm{B} 2$ phase. It could be ascribed to the formation of dislocations, which would obstacle the phase transformation from B19 to BCO phase [39] as observed in Cu-Al-Ni SMAs [40]. In addition, both energy release induced by the formation of dislocations and high local temperature would drive the $\mathrm{BCO} \rightarrow \mathrm{B} 2$ reverse transformation.

At the section $13.0 \mathrm{~nm}$ away from the impact section, as shown in Figure 5, the increase of stress from about $0.1 \mathrm{GPa}$ at $2.6 \mathrm{ps}$ to about $1.1 \mathrm{GPa}$ at $3.2 \mathrm{ps}$ indicated the arrival of stress wave. The stress induced B19 phase was observed. After that the stress increased again from $1.0 \mathrm{GPa}$ at $3.8 \mathrm{ps}$ to about $2.5 \mathrm{GPa}$ at $4.8 \mathrm{ps}$. At $5.8 \mathrm{ps}$, it increased to the peak value of about $3.5 \mathrm{GPa}$, and then decreased slowly to about $0.4 \mathrm{GPa}$ at $13.0 \mathrm{ps}$. The corresponding temperature increased from about $500 \mathrm{~K}$ at 3.6 ps to about $591 \mathrm{~K}$ at $6.4 \mathrm{ps}$, and then slowly decreased to about $513 \mathrm{~K}$ at $13 \mathrm{ps}$. Since the stress was lower than the B19 to B19' phase transformation stress due to the stress dissipation during propagation, the $\mathrm{B} 19 \rightarrow \mathrm{B} 19^{\prime}$ phase transformation was not observed in this layer. The corresponding CNA value stayed at about 3.5 before 5 ps, indicating no B19' phase formed. However, the CNA value increased slightly to about 3.8 at 5.8 ps, which could be ascribed to the increase of surface effect induced by the increase of temperature [22]. After that, the CNA value 
quickly decreased to about 3.5 due to the decrease of temperature, indicating no phase transformation during the shock propagation.

Figure 6 shows the stress histories at various NiTi nano-pillar cross sections along the impact direction to clearly show the stress attenuation in the NiTi nano-pillar. As shown in Figure 6(a), three peaks were observed during the stress wave propagation. The first peak decreased rapidly because of the phase transformation from the B19 phase to the BCO phase as depicted in Figures 3-5. After propagating a distance of about $7.0 \mathrm{~nm}$, the first peak disappeared. In addition, the initial stress plateau developed to the second peak at the cross section layer at $4.6 \mathrm{~nm}$. Similarly, due to the B19 $\rightarrow$ BCO phase transformation, the second peak stress decreased continuously during propagation. Meanwhile, the difference in stress wave speeds leaded to the fast elastic stress wave of the BCO phase chasing after its slow phase plastic stress wave, resulting in the formation of the third peak. As shown in Figure 6(b), during the stress wave propagation the first peak disappeared and the second peak became the 'first peak' in the cross section layer 7-13 $\mathrm{nm}$ away from the impact section and finally disappeared beyond $14.2 \mathrm{~nm}$. Similarly, the third peak experienced the third $\rightarrow$ second $\rightarrow$ first peak evolution. Beside some slightly changes caused by atomic oscillations, the stress profiles beyond the cross section layer $13 \mathrm{~nm}$ away from the impact section were similar because of no stress induced phase transformation in this region.

Figure 7 shows the propagation of stress waves and the corresponding atomic structures in the NiTi nano-pillar. Here, the stresses were averaged on a group of atoms (both $\mathrm{Ni}$ and $\mathrm{Ti}$ atoms) in each plate with a thickness of $1.2 \mathrm{~nm}$. As shown in Figure 7(a), it was clearly observed that the first peak and the second peak disappeared gradually with the propagation of stress wave, and the stress wave structure was developed into a much ramped triangle with the third peak after 5.0 ps. As shown in Figure 7(b), after 0.6 ps, the stress at the shock front increased abruptly to about $8.6 \mathrm{GPa}$. This stress value is,much higher than the B19 $\rightarrow$ B19' phase transformation stress under uniaxial compression at a strain rate of about $10^{9} \mathrm{~s}^{-1}$, indicating the strain rate dependent effect [22]. Because of phase transformation, the first stress peak dropped quickly to a level of about 5.0 GPa at $1.0 \mathrm{ps,}$ and the stress split was observed at the stress wave front at $1.4 \mathrm{ps}$. This stress wave split was induced by the separation of stress waves of various transformed phases with different wave speed, i.e. the separation of the fast B19 phase wave near stress wave front and the following slow BCO phase wave. Note that the first stress wave peak disappeared after 2.0 ps. It was clearly observed that the wave length of the first stress wave peak was close to that of the atomic oscillation induced noise. Thus, it is assumed that the disappearance of stress wave peaks is caused by the stress dissipation through the atomic oscillations. Due to the increase of the volume ratio of the $\mathrm{BCO}$ phase in the large deformation area as well as the formation and development of dislocations facilitated by the adiabatic temperature rising, the stress plateau decreased continually before 3.0 ps as shown in Figure 7(b). Then newly formed defects were observed as given in Figure $7(\mathrm{c})$, leading to the 
(a)

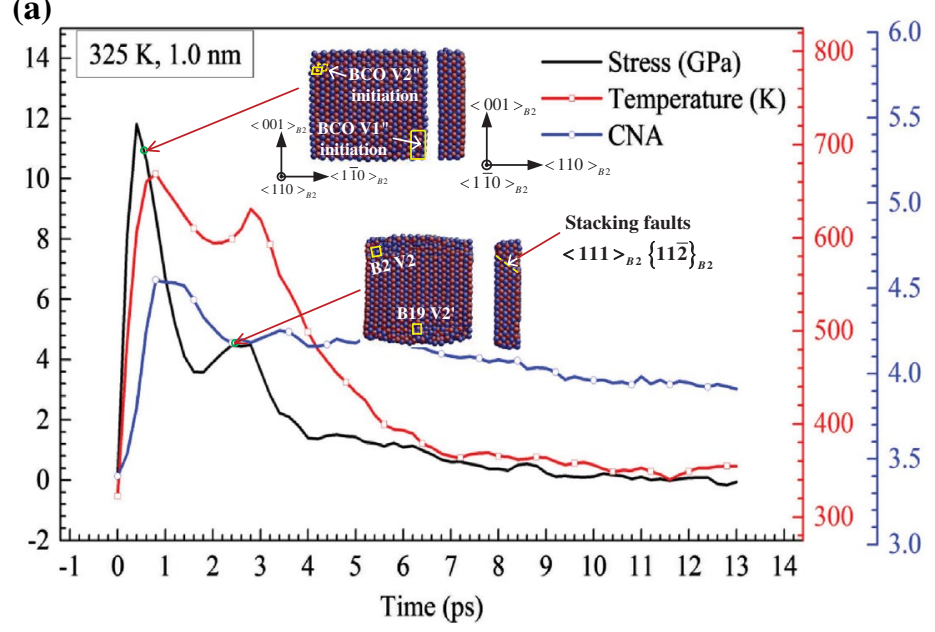

(b)

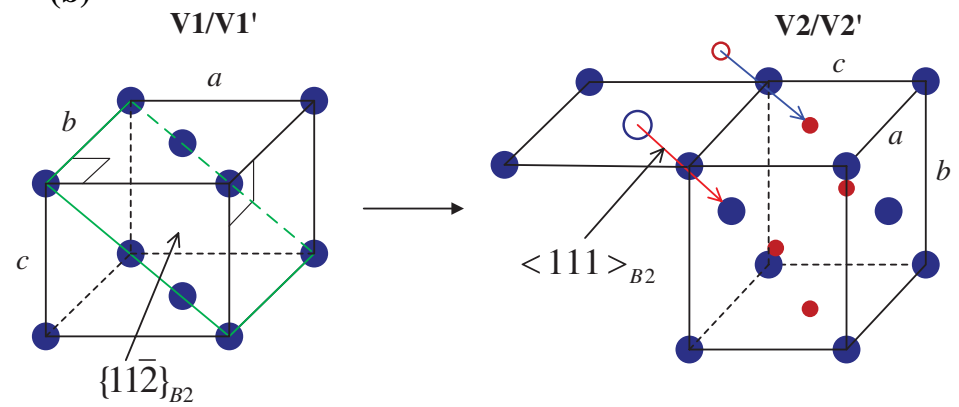

Figure 8. (colour online) (a) Stress history, cross section atomic structure, temperature evolution and corresponding CNA history at the impact end area at the initial temperature $325 \mathrm{~K}$. (b) B2 and $\mathrm{B} 19$ variants in this cross section layer (B2 V1 and V2 variants with $a=b, \mathrm{~B} 19 \mathrm{~V} 1$ ' and V2' variants with $a \neq b$ ).

slightly drop of stress at $3.2 \mathrm{ps}$. Note that the stress peak near the stress wave front disappeared after 3.4 ps. Meanwhile, the relative fast $\mathrm{BCO}$ phase transformation wave caught up with the relative slow BCO plastic wave, leading to a stress wave structure with single peak. After $4.0 \mathrm{ps}$, the stress wave peak went through the large deformation area and the peak value of stress was not sufficient high to induce the $\mathrm{B} 19 \rightarrow \mathrm{B} 19^{\prime}$ phase transformation. As a result, the dissipation of stress wave in the NiTi nano-pillar was negligible after 5.0 ps as shown in Figure 7(a).

\subsection{Phase transformation and twinning deformation}

In this section, the temperature effect on the dynamic behaviour of NiTi nanopillar under impact was investigated. The initial thermal equilibrium temperature was set to $325 \mathrm{~K}$. After the thermal equilibrium, due to the phase transformation from initial B2 phase to B19 phase induced by the free surface stress, the initial 


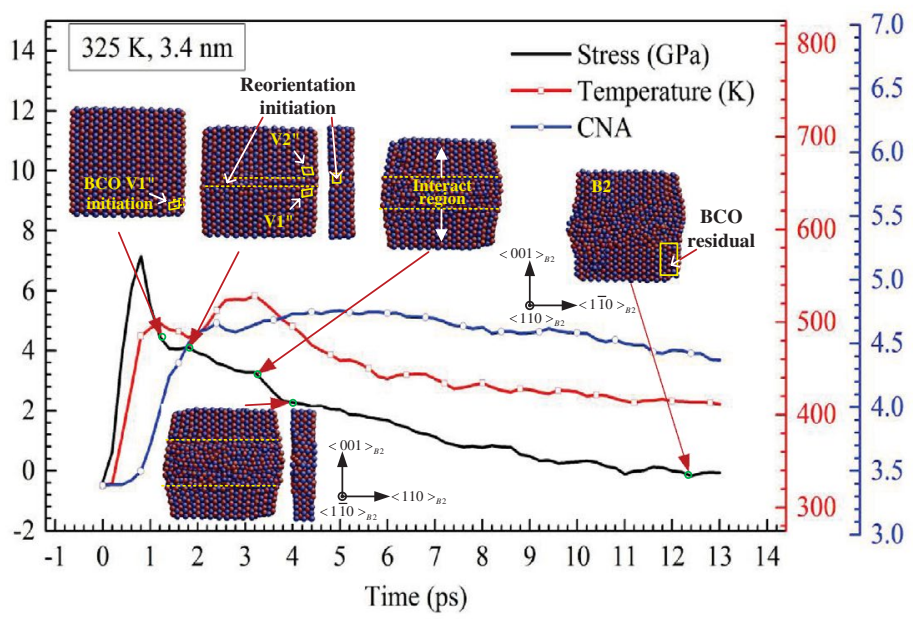

$3.4 \mathrm{~nm}$ from

Impact end impact end

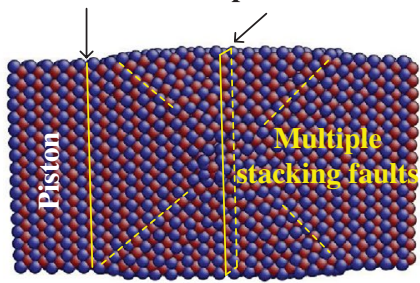

$3.2 \mathrm{ps}$
$3.4 \mathrm{~nm}$ from Impact end impact end

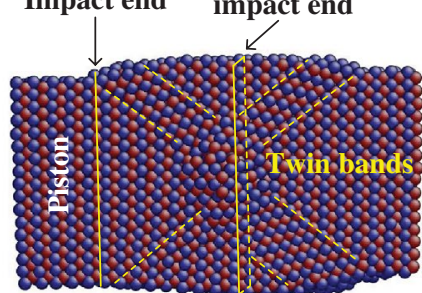

$12.6 \mathrm{ps}$

Figure 9. (colour online) (a) Stress history, cross section atomic structure, temperature evolution and corresponding CNA history at the large deformation area at initial temperature $325 \mathrm{~K}$. (b) Formation and evolution of the twin bands.

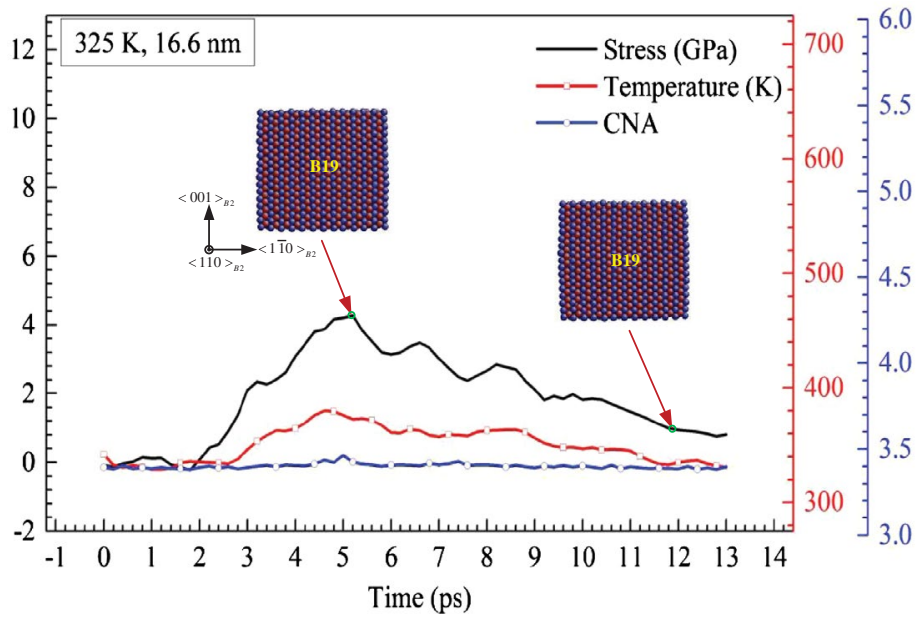

Figure 10. (colour online) Stress history, cross section atomic structure, temperature evolution and corresponding CNA history at area far away from the impact end at initial temperature $325 \mathrm{~K}$. 


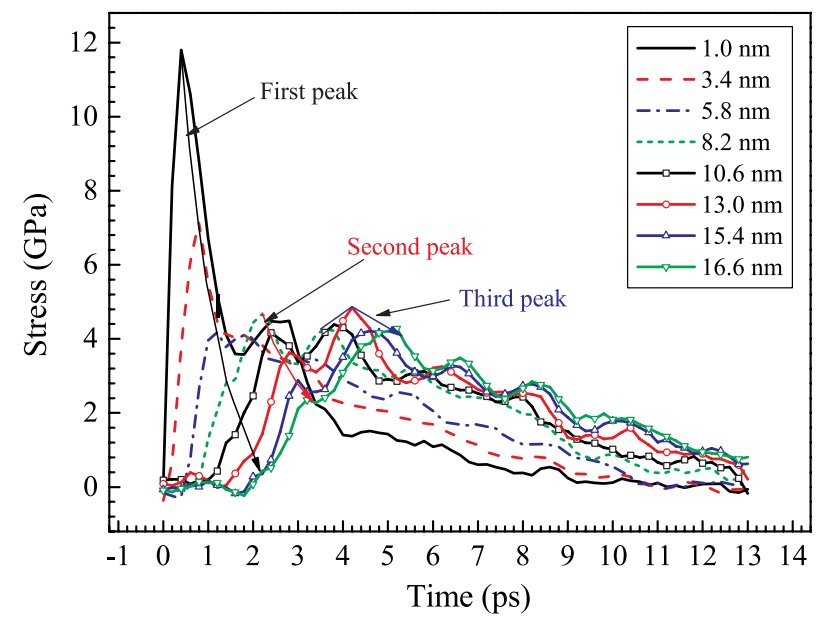

Figure 11. (colour online) Stress histories of different NiTi nano-pillar cross section layers from 1.0 to $16.6 \mathrm{~nm}$ away from impact end at initial temperature $325 \mathrm{~K}$.

length of the NiTi nano-pillar decreased from about $50.2 \mathrm{~nm}$ to about $48.8 \mathrm{~nm}$. This phenomenon is consistent with the study by Mirzaeifar et al. [41] and our previous study [22].

Figures 8-10 show the stress histories, the CNA histories, the atomic structure evolutions, and the temperature evolutions of the near impact end area (about $1.0 \mathrm{~nm}$ away from the impact end), the large deformation area ( $3.4 \mathrm{~nm}$ away from the impact end), and the rear area (16.6 $\mathrm{nm}$ away from the impact end) along the shock direction, respectively. As shown in Figure 8(a), during the impact the stress of this cross section layer increased abruptly to about $11.8 \mathrm{GPa}$ at $0.4 \mathrm{ps}$ and then dropped quickly to about $3.6 \mathrm{GPa}$ at $1.6 \mathrm{ps}$. During the decrease of stress, both the stress induced $\mathrm{BCO} V 1 "$ and V2" variants were observed, leading to the abrupt increase of CNA value from about 3.4 to about 4.5 at $0.8 \mathrm{ps}$. The atomic structure changed from the $\mathrm{B} 2 \mathrm{~V} 1$ variant to the $\mathrm{V} 2$ variant or the $\mathrm{B} 19 \mathrm{V1}$ ' variant to the V2' variant, which were dependent to the local temperature and stress state, were achieved through the slide of atoms on crystal plane of $\left\{\begin{array}{lll}1 & 1 & \overline{2}\end{array}\right\}_{\mathrm{B} 2}$ in the direction of $\langle 111\rangle_{\mathrm{B} 2}$ as depicted in Figure 8(b). After that, the stress slightly increased to about $4.5 \mathrm{GPa}$ at $2.4 \mathrm{ps}$. As shown in Figure 8(a), due to adiabatic temperature rising, the facilitation of atoms migration caused the formations of stacking faults as well as the $\mathrm{B} 2 \mathrm{~V} 2$ and the $\mathrm{B} 19 \mathrm{~V} 2$ ' variants, leading to the sharp drop of stress before 3.0 ps followed by continuous slow unloading process. Moreover, the work of shock wave and the energy release during the formation of stacking faults also caused the temperature rising from about $590 \mathrm{~K}$ at $2.0 \mathrm{ps}$ to about $630 \mathrm{~K}$ at $2.6 \mathrm{ps}$.

Figure 9 shows the stress history, the corresponding atomic structure evolution, the twin bands evolution, the temperature evolution, and the CNA history at the cross section layer about $3.4 \mathrm{~nm}$ away from the impact end. As shown in Figure 9(a), at the beginning the stress increased abruptly to about $7.2 \mathrm{GPa}$ at $0.8 \mathrm{ps}$ and the corresponding temperature increased from about $330 \mathrm{~K}$ to about $499 \mathrm{~K}$ at $1.2 \mathrm{ps}$. 
(a)

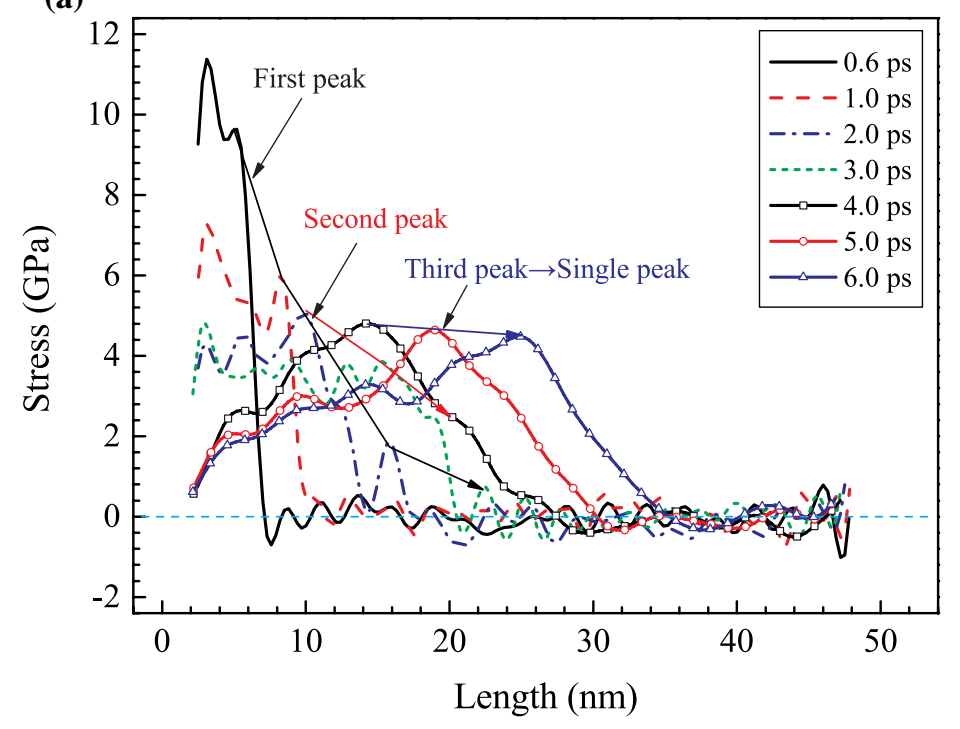

(b)
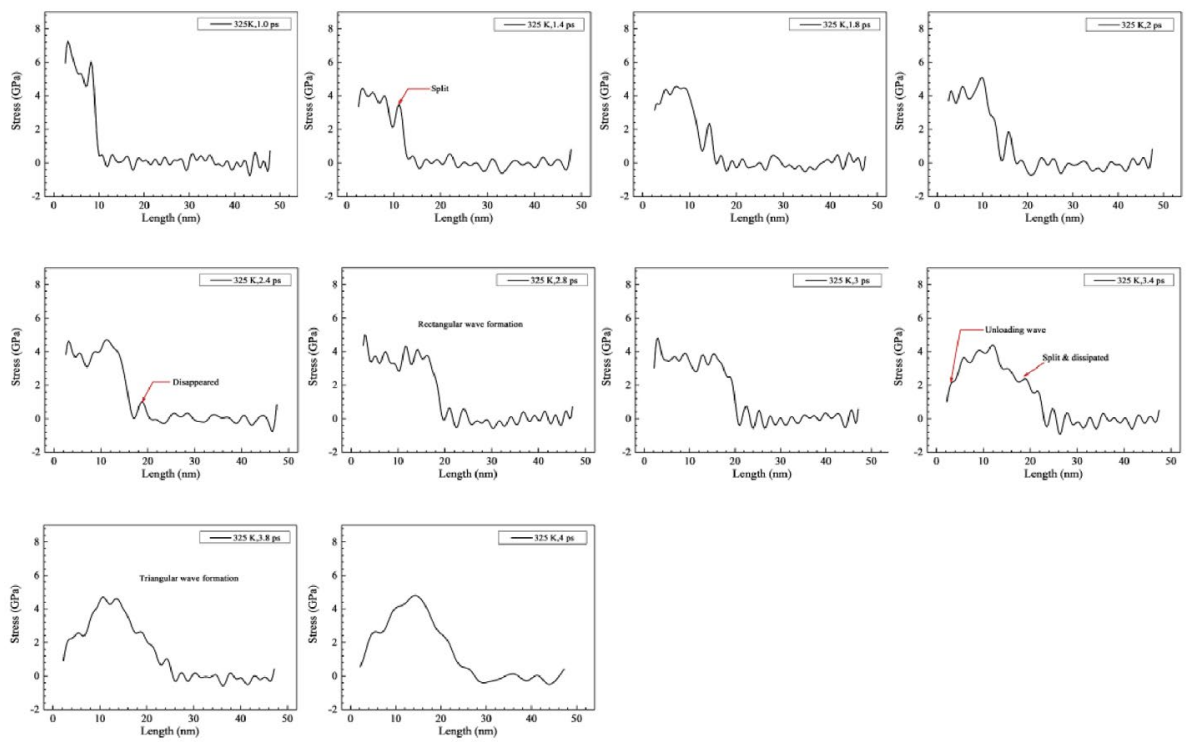

Figure 12. (colour online) (a) Stress distribution along the NiTi nano-pillar at different time at initial temperature $325 \mathrm{~K}$. (b) Detailed stress distribution from 1.0 to 4.0 ps after impact, showing the geometry change of stress wave from cubic to triangular.

Then the stress dropped quickly to about $4.1 \mathrm{GPa}$ at $1.6 \mathrm{ps}$ while the corresponding temperature slightly decreased to about $483 \mathrm{~K}$ at $1.8 \mathrm{ps}$. During the decrease of stress, the stress induced BCO V1" was observed due to the relatively lower stress level, leading to the increase of CNA value from about 3.4 to about 4.7 at 2.4 ps. However, both the BCO V1" and the V2" variants were observed at 2.0 ps, where the crystal reorientation began to initiate. The V2" variant was only observed at the 
boundary of reorientation band due to the large local deformation. After that, the stress decreased slightly from about $4.1 \mathrm{GPa}$ at $1.8 \mathrm{ps}$ to about $3.3 \mathrm{GPa}$ at $3.2 \mathrm{ps}$, which was induced by the increase of ratio of the BCO phase and the formation of stacking faults as shown in Figure 9(a) and (b). Moreover, the corresponding temperature increased from about $483 \mathrm{~K}$ to about $528 \mathrm{~K}$ at $3.2 \mathrm{ps}$ due to the formation of the BCO phase and the plastic deformation. Then, the expansion of the interact region of twin bands leaded to the sharp drop of stress from about $3.3 \mathrm{GPa}$ at 3.2 ps to about $2.3 \mathrm{GPa}$ at 3.8 ps before unloading. The corresponding CNA value increased from about 4.6 to about 4.8 at 4.0 ps because of the increase of ratio of the $\mathrm{BCO}$ phase and the expansion of twin bands. During the unloading process, the reverse phase transformation from the $\mathrm{BCO}$ to the $\mathrm{B} 2$ phase was observed because of the adiabatic temperature rising as shown in Figure 9(a), and the energy release induced by the formation of twin bands with twin plane $\left\{\begin{array}{lll}1 & 1 & \overline{2}\end{array}\right\}_{\mathrm{B} 2}$. Note that there was still residual BCO phase after the unloading process, which was different from that in the case of $500 \mathrm{~K}$, leading to a relative large CNA value of about 4.4. This could be understood by two aspects. First, as shown in Figure 9(a), due to the endothermic reverse phase transformation from the $\mathrm{BCO}$ to the $\mathrm{B} 2$ phase and the heat transfer, the temperature decreased during the reverse transformation process. The local temperature decreased to about $438 \mathrm{~K}$ at $6 \mathrm{ps}$, implying that the residual $\mathrm{BCO}$ phase was stable at this stress state according to the phase diagram of NiTi [22]. In addition, after the completion of B2 twin bands formation, there was no energy release to drive the $\mathrm{BCO} \rightarrow \mathrm{B} 19 \rightarrow \mathrm{B} 2$ reverse phase transformation. As a result, partial residual $\mathrm{BCO}$ phase was observed finally.

Figure 10 shows the stress history, the corresponding atomic structure evolution, the temperature evolution, and the CNA history at the cross section layer about $16.6 \mathrm{~nm}$ away from the impact end. As shown in Figure 10, the stress began to increase at about 1.8 ps to about $2.4 \mathrm{GPa}$ at $3.2 \mathrm{ps}$, and the corresponding temperature increased from about $325 \mathrm{~K}$ at 2.6 ps to about $362 \mathrm{~K}$ at $3.6 \mathrm{ps}$. After a narrow stress plateau, the stress increased again at 3.4 ps to about $4.3 \mathrm{GPa}$ at $5.2 \mathrm{ps}$ and the corresponding temperature increased to about $380 \mathrm{~K}$ at $4.8 \mathrm{ps}$. Then the stress decreased continuously to about $0.5 \mathrm{GPa}$ at $13.0 \mathrm{ps}$ after the impact and the corresponding temperature decreased to about $333 \mathrm{~K}$. There was no obvious atomic structure change because the stress of this section was not sufficient high to induce phase transformation and plastic deformation. The corresponding CNA value stayed at about 3.4, indicating no phase transformation during the shock wave propagation, which was coincident with the observation of atomistic structures.

The stress histories of various cross section layers along the impact direction are shown in Figure 11. The stress attenuation behaviour at $325 \mathrm{~K}$ was similar to that at the case of $500 \mathrm{~K}$. Three peaks were observed during the stress wave propagation. The first peak decreased rapidly and disappeared totally at the cross section layer of $10.2 \mathrm{~nm}$ along the impact direction due to stress dissipation through atomic oscillations, phase transformation and plastic deformation. The second peak experienced the same change as the first peak as shown in Figure 11. Similar 
with the case of $500 \mathrm{~K}$, the third peak was formed due to the catch up of the slow BCO phase's plastic wave by the fast BCO's elastic wave. It was clearly shown that beyond $15.4 \mathrm{~nm}$ away from the impact end, the change of the stress structure was negligible except some small differences caused by atomic oscillations, indicating no obvious atomic structure transformation.

Figure 12 shows the stress attenuation behaviour along the NiTi nano-pillar. As shown in Figure 12(a), the first peak disappeared after 3.0 ps while the second peak disappeared after 4.0 ps. The structure of stress wave changed from the initially rectangular wave to the final triangular wave. The detail of the stress wave development is shown in Figure 12(b). As shown in Figure 12(b), the stress wave split, which was induced by the difference in various phase wave speeds, e.g. the B19 with fast speed wave at the stress wave and the BCO with slow stress wave speed near impact end area, was observed between $1.0 \mathrm{ps}$ and 1.4 ps after impact. Similar with the case of $500 \mathrm{~K}$, the isolated stress peak disappeared quickly at 2.4 ps due to atomic oscillations induced dissipation at the front of the stress wave. The unloading stress wave was observed after the remove of extra loading at 3.0 ps Because of the reverse transformation from the $\mathrm{BCO}$ phase to the B19 phase and then to the B2 phase at the near impact end, which were induced by the adiabatic temperature rising and the energy release during the formation of twin bands while unloading, the fast stress wave of the B19 phase caught up with the slow stress wave of the BCO phase and the plastic stress wave, leading to the formation of the triangular like stress wave structure after 3.8 ps as shown in Figure 12(b).

\subsection{Temperature effect on plastic deformation}

In the simulation, two different plastic deformation modes were observed, i.e. the deformation twinning mode with the twin plane of $\left\{\begin{array}{lll}1 & 1 & \overline{2}\end{array}\right\}_{\mathrm{B} 2}$ [17] under the low temperature condition of $325 \mathrm{~K}$ and the dislocation slide mode with the slide plane of $\{011\}_{B 2}$ and the slide direction of $<\overline{1} 00>_{B 2}$ [35] at the high temperature condition of $500 \mathrm{~K}$. The plastic deformation behaviour at 325 and $500 \mathrm{~K}$ are shown in Figure 13(a) and (b), respectively. As shown in Figure 13(a), the stacking faults were clearly observed at 2.0 ps near the impact end area. At 2.4 ps, a second stacking faults line was observed and began to interact with the first one. Then multiple stacking fault lines were observed at $3.4 \mathrm{ps}$. After that, the latest formed stacking faults developed to the twin bands at $7.8 \mathrm{ps}$. The twin bands interacted at the centre of the NiTi nano-pillar, leading to the atomic structure disorder at the interact region. At 8.4 ps, the first formed stacking faults developed to a new twin band, and the deformation twinning plasticity was kept after unloading. As shown in Figure 13(b), at $1.8 \mathrm{ps}$ atom $i$ and the rest three atoms highlighted with yellow colour consisted of a crystal cell while impact at $500 \mathrm{~K}$. As time progressed, atom $i$ and atom $j$ (highlighted with grey colour) on the crystal plane of $\left\{\begin{array}{llll}0 & 1 & 1\end{array}\right\}_{\mathrm{B} 2}$ moved in the direction of $\langle\overline{1} 00\rangle_{\mathrm{B} 2}$, leading to the replacement of the atom $i$ 

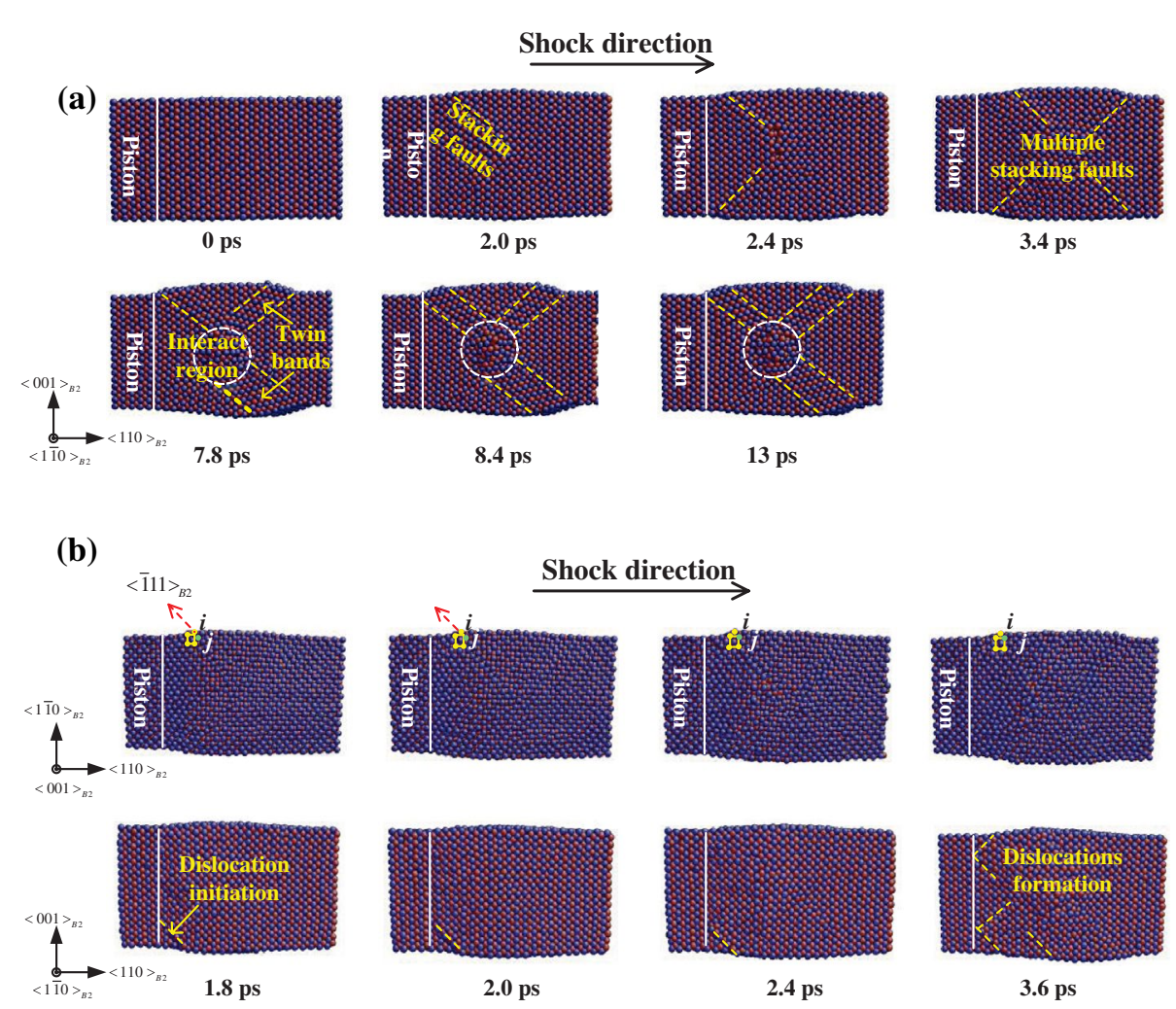

Figure 13. (colour online) (a) Deformation twinning mode at initial temperature $325 \mathrm{~K}$. (b) Dislocation deformation mode at initial temperature $500 \mathrm{~K}$.

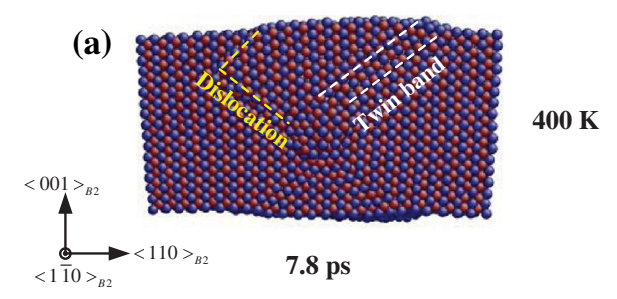

(b)

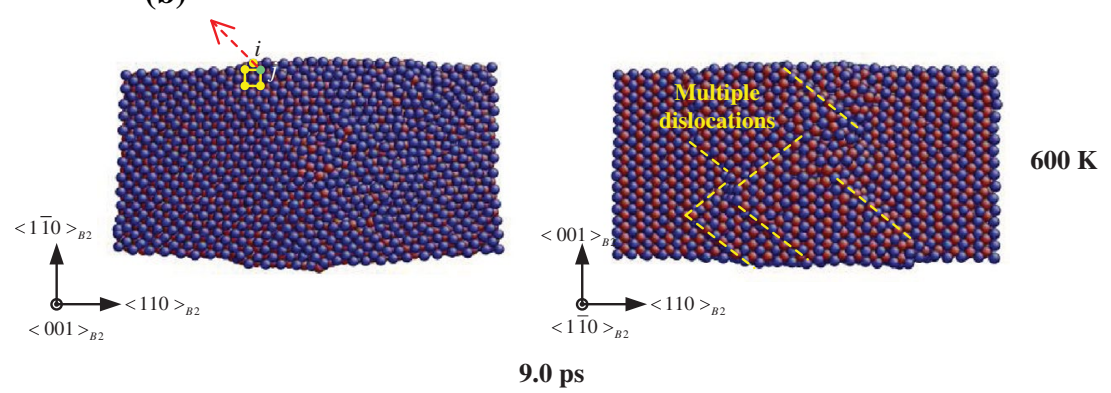

Figure 14. (colour online) (a) Deformation twinning mode at initial temperature $400 \mathrm{~K}$. (b) Dislocation deformation mode at initial temperature $600 \mathrm{~K}$. 
with the atom $j$ at $2.4 \mathrm{ps}$ and the formation of a new crystal cell. The newly formed dislocation structure was kept after unloading.

The dynamic behaviour of the NiTi nano-pillar at thermal equilibrium temperatures of 400 and $600 \mathrm{~K}$ were also simulated to further understand the temperature effects on the plastic deformation behaviour of the NiTi nano-pillar. The residual plastic deformations at 400 and $600 \mathrm{~K}$ are shown in Figure 14(a) and (b), respectively. As shown in Figure 14(a), both dislocation deformation mode and deformation twinning mode were observed at $7.8 \mathrm{ps}$ after impact at the temperature of $400 \mathrm{~K}$. However, only dislocation deformation mode with distinctive arrowhead morphology, which was also observed by Norfleet et al. [42], was observed at the temperature of $600 \mathrm{~K}$ at $9.0 \mathrm{ps}$ after shock as shown in Figure 14(b). According to the simulation results, it could be seen that under shock condition deformation twinning mode was more likely to take place at low temperature while dislocation was the preferred plastic deformation behaviour of the NiTi nano-pillar at high temperature, showing similar temperature dependent plasticity of the NiTi nano-pillar under quasi-static loading condition [22].

\section{Summary}

In the present work, the shock behaviour of the NiTi nano-pillar under impact was studied through MD simulations. The temperature and pressure dependent phase transformation, plasticity mechanism, and stress attenuation behaviour during the shock wave propagation of the NiTi nano-pillar were investigated. Two sliding modes were observed at various stress level for the formation of the BCO phase, and twinning and dislocation were dominant plasticity of $\mathrm{NiTi}$ at relative low and high temperature, respectively. More interestingly, the stress wave with multiple peaks structure was observed during its propagation in the NiTi nano-pillar due to the complex phase transformation and plasticity. The energy dissipation induced by phase transformation and plasticity leaded to the attenuation and consequently disappearance of stress peaks, while the formed phases with various wave speeds resulted in the increase of the third peak and the stress plateau.

\section{Acknowledgements}

The authors wish to express their appreciation to Professor T. Zhu at Georgia Institute of Technology for providing the improved potential of NiTi.

\section{Disclosure statement}

No potential conflict of interest was reported by the authors.

\section{Funding}

This work was supported by National Natural Science Foundation of China [grant number 11332011], [grant number 11402277]. 


\section{References}

[1] K. Otsuka and C.M. Wayman, Shape Memory Materials, Cambridge University Press, Cambridge, 1998.

[2] D. Tw, Engineering Aspects of Shape Memory Alloys, Butterworth-Heinemann, London, 1990.

[3] K. Bhattacharya, Microstructure of Martensite, Why it Forms and How it Gives Rise to the Shape-memory Effect, Oxford University Press, Oxford, 2003.

[4] L. McDonald Schetky, Shape memory alloy applications in space systems, Mater. Des. 12 (1991), pp. 29-32.

[5] A. Biesiekierski, J. Wang, M. Abdel-Hady Gepreel, and C. Wen, A New Look at Biomedical Ti-based Shape Memory Alloys, Acta Biomater. 8 (2012), pp. 1661-1669.

[6] A. Pequegnat, M. Daly, J. Wang, Y. Zhou, and M.I. Khan, Dynamic actuation of a novel laser-processed NiTi linear actuator, Smart Mater. Struct. 21 (2012), p. 094004.

[7] S. Nemat-Nasser and W.-G. Guo, Superelastic and cyclic response of NiTi SMA at various strain rates and temperatures, Mech. Mater. 38 (2006), pp. 463-474.

[8] N. Zotov, V. Marzynkevitsch, and E.J. Mittemeijer, Evaluation of kinetic equations describing the martensite-austenite phase transformation in NiTi shape memory alloys, J. Alloys Compd. 616 (2014), pp. 385-393.

[9] Y. Liu, Y. Li, K.T. Ramesh, and J. Van Humbeeck, High strain rate deformation of martensitic NiTi shape memory alloy, Scr. Mater. 41 (1999), pp. 89-95.

[10] X. Wang, Y. Bellouard, and J.J. Vlassak, Laser annealing of amorphous NiTi shape memory alloy thin films to locally induce shape memory properties, Acta Mater. 53 (2005), pp. 4955-4961.

[11] D. Gunderov, A. Lukyanov, E. Prokofiev, A. Kilmametov, V. Pushin, and R. Valiev, Mechanical properties and martensitic transformations in nanocrystalline Ti49.4Ni50.6 alloy produced by high-pressure torsion, Mater. Sci. Eng. A 503 (2009), pp. 75-77.

[12] T. Simon, A. Kröger, C. Somsen, A. Dlouhy, and G. Eggeler, On the multiplication of dislocations during martensitic transformations in NiTi shape memory alloys, Acta Mater. 58 (2010), pp. 1850-1860.

[13] W.W. Chen, Q. Wu, J.H. Kang, and N.A. Winfree, Compressive superelastic behavior of a NiTi shape memory alloy at strain rates of 0.001-750 $\mathrm{s}^{-1}$, Int. J. Solids Struct. 38 (2001), pp. 8989-8998.

[14] J.P.L. McDonald Schetky, The 'quiet' alloys, in Machine Design, 1978, pp. 202-206.

[15] S. Nemat-Nasser, J.-Y. Choi, W.-G. Guo, and J.B. Isaacs, Very high strain-rate response of a NiTi shape-memory alloy, Mech. Mater. 37 (2005), pp. 287-298.

[16] Y. Liao, C. Ye, D. Lin, S. Suslov, and G.J. Cheng, Deformation induced martensite in NiTi and its shape memory effects generated by low temperature laser shock peening, J. Appl. Phys. 112 (2012), p. 033515.

[17] Y. Zhong, K. Gall, and T. Zhu, Atomistic characterization of pseudoelasticity and shape memory in NiTi nanopillars, Acta Mater. 60 (2012), pp. 6301-6311.

[18] C.D. Wu, P.H. Sung, and T.H. Fang, Study of deformation and shape recovery of NiTi nanowires under torsion, J. Mol. Model. 19 (2013), pp. 1883-1890.

[19] T. Sato, K.-I. Saitoh, and N. Shinke, Molecular dynamics study on microscopic mechanism for phase transformation of Ni-Ti alloy, Modell. Simul. Mater. Sci. Eng. 14 (2006), pp. S39-S46.

[20] D. Mutter and P. Nielaba, Simulation of the thermally induced austenitic phase transition in NiTi nanoparticles, Eur. Phys. J. B 84 (2011), pp. 109-113.

[21] Y. Zhong, K. Gall, and T. Zhu, Atomistic study of nanotwins in NiTi shape memory alloys, J. Appl. Phys. 110 (2011), p. 033532. 
[22] Q. Yin, X. Wu, C. Huang, X. Wang, and Y. Wei, Atomistic study of temperature and strain rate-dependent phase transformation behaviour of NiTi shape memory alloy under uniaxial compression, Philos. Mag. 95 (2015), pp. 2491-2512.

[23] S. Nemat-Nasser, Y. Su, W.-G. Guo, and J. Isaacs, Experimental characterization and micromechanical modeling of superelastic response of a porous NiTi shape-memory alloy, J. Mech. Phys. Solids 53 (2005), pp. 2320-2346.

[24] S. Plimpton, Fast parallel algorithms for short-range molecular dynamics, J. Comput. Phys. 117 (1995), pp. 1-19.

[25] W.S. Lai and B.X. Liu, Lattice stability of some Ni-Ti alloy phases versus their chemical composition and disordering, J. Phys.: Conden. Matter 12 (2000), p. L53.

[26] W.G. Hoover, Canonical dynamics: Equilibrium phase-space distributions, Phys. Rev. A 31 (1985), pp. 1695-1697.

[27] F. Yuan and X. Wu, Shock response of nanotwinned copper from large-scale molecular dynamics simulations, Phys. Rev. B 86 (2012), p. 134108.

[28] F. Daniel and J. Hannes, Systematic analysis of local atomic strucure combined with $3 D$ computer graphics, Comput. Mater. Sci. 2 (1994), pp. 279-286.

[29] H. Tsuzuki, P.S. Branicio, and J.P. Rino, Structural characterization of deformed crystals by analysis of common atomic neighborhood, Comput. Phys. Commun. 177 (2007), pp. 518-523.

[30] T.M. Brill, S. Mittelbach, W. Assmus, M. Mullner, and B. Luthi, Elastic properties of NiTi, J. Phys. Condens. Matter 3 (1991), pp. 9621-9627.

[31] N. Hatcher, O.Y. Kontsevoi, and A.J. Freeman, Role of elastic and shear stabilities in the martensitic transformation path of NiTi, Phys. Rev. B 80 (2009), p. 144203.

[32] M.F.X. Wagner and W. Windl, Lattice stability, elastic constants and macroscopic moduli of NiTi martensites from first principles, Acta Mater. 56 (2008), pp. 6232-6245.

[33] X. Huang, G.J. Ackland, and K.M. Rabe, Crystal structures and shape-memory behaviour of NiTi, Nat. Mater. 2 (2003), pp. 307-311.

[34] A.P. Stebner, D.W. Brown, and L.C. Brinson, Measurement of elastic constants of monoclinic nickel-titanium and validation of first principles calculations, Appl. Phys. Lett. 102 (2013), p. 211908.

[35] X. Ren and K. Otsuka, The role of softening in elastic constant c44 in martensitic transformation, Scr. Mater. 38 (1998), pp. 1669-1675.

[36] T. Onda, Y. Bando, T. Ohba, and K. Otsuka, Electron microscopy study of twins in martensite in a Ti-50.0 at\%Ni alloy, Mater. Trans., JIM 33 (1992), pp. 354-359.

[37] J.X. Zhang, M. Sato, and A. Ishida, Deformation mechanism of martensite in Ti-rich Ti-Ni shape memory alloy thin films, Acta Mater. 54 (2006), pp. 1185-1198.

[38] T. Ezaz, H. Sehitoglu, and H.J. Maier, Energetics of twinning in martensitic NiTi, Acta Mater. 59 (2011), pp. 5893-5904.

[39] S. Miyazaki, Y. Igo, and K. Otsuka, Effect of thermal cycling on the transformation temperatures of Ti $\bullet$ Ni alloys, Acta Metall. 34 (1986), pp. 2045-2051.

[40] A. Ibarra, J. San Juan, E.H. Bocanegra, and M.L. Nó, Evolution of microstructure and thermomechanical properties during superelastic compression cycling in $\mathrm{Cu}-\mathrm{Al}-\mathrm{Ni}$ single crystals, Acta Mater. 55 (2007), pp. 4789-4798.

[41] R. Mirzaeifar, K. Gall, T. Zhu, A. Yavari, and R. DesRoches, Structural transformations in NiTi shape memory alloy nanowires, J. Appl. Phys. 115 (2014), p. 194307.

[42] D.M. Norfleet, P.M. Sarosi, S. Manchiraju, M.F.X. Wagner, M.D. Uchic, P.M. Anderson, and M.J. Mills, Transformation-induced plasticity during pseudoelastic deformation in Ni-Ti microcrystals, Acta Mater. 57 (2009), pp. 3549-3561. 